M. Köhler, I. Boxx, K.P. Geigle, W. Meier

Simultaneous planar measurements of soot structure and velocity fields in a turbulent lifted jet flame at $3-\mathrm{kHz}$

Appl. Phys. B 103 (2011), 271-279.

The original publication is available at www.springerlink.com

http://dx.doi.org/10.1007/s00340-011-4549-5 


\title{
Simultaneous planar measurements of soot structure and velocity fields in a turbulent lifted jet flame at $3-\mathrm{kHz}$
}

\author{
M. Köhler*, I. Boxx, K. P. Geigle, W. Meier
}

Deutsches Zentrum für Luft- und Raumfahrt (DLR), Institut für Verbrennungstechnik, Stuttgart

*Corresponding author:

Dr. Markus Köhler

Institut für Verbrennungstechnik, Deutsches Zentrum

für Luft-und Raumfahrt (DLR), Pfaffenwaldring 38-40

70569 Stuttgart, Germany

Phone: $++49 / 711 / 6862-756$

Fax: ++49/711/6862-578

Email: M.Koehler@dlr.de

\section{Other authors:}

Dr. Isaac Boxx

Phone: $++49 / 711 / 6862-732$

Fax: ++49/711/6862-578

Email: isaac.boxx@dlr.de

Dr. Klaus-Peter Geigle

Phone: $++49 / 711 / 6862-398$

Fax: ++49/711/6862-578

Email: KlausPeter.Geigle@dlr.de

Dr. Wolfgang Meier

Phone: ++49/711/6862-397

Fax: ++49/711/6862-578

Email: wolfgang.meier@dlr.de 


\begin{abstract}
We describe a newly developed combustion diagnostic for the simultaneous planar imaging of soot structure and velocity fields in a highly sooting, lifted turbulent jet flame at 3000 frames per second, or two orders of magnitude faster than "conventional" laser imaging systems. This diagnostic uses short pulse duration (8 ns), frequency-doubled, diode-pumped solid state (DPSS) lasers to excite laserinduced incandescence (LII) at $3 \mathrm{kHz}$, which is then imaged onto a high framerate CMOS camera. A second (dual-cavity) DPSS laser and CMOS camera form the basis of a particle image velocity (PIV) system used to acquire 2-component velocity field in the flame. The LII response curve (measured in a laminar propane diffusion flame) is presented and the combined diagnostics then applied in a heavily sooting lifted turbulent jet flame. The potential challenges and rewards of application of this combined imaging technique at high speeds are discussed.
\end{abstract}




\section{Introduction}

Laser-induced incandescence (LII) is a minimally intrusive diagnostic technique used to study soot structure and volume fraction in flames and combustion exhaust gases [1,2]. In this technique, soot particles are rapidly heated to $4000 \mathrm{~K}$ (or higher) using a high-intensity pulsed laser. The resulting incandescence is captured on a photo-sensor, typically a photomultiplier tube or intensified CCD camera. The minimally-intrusive nature of LII, with its ability to take both point and planar in-situ measurements of soot volume fraction and particle size make it a diagnostic technique of both fundamental and applied technical interest. It has been used extensively to study soot distributions in flames ranging from laboratory-scale test flames [3,4] to automotive engines [5-7], high-pressure industrial-type combustors [8-10] and aero engine exhaust $[11,12]$. A thorough review of the theoretical basis for the LII technique can be found in [13] and [14].

Soot formation in a turbulent flame is a complex, multi-parameter dependent phenomenon. Studies so far $[15,16]$ have yielded new insight into the thermo-kinetic processes responsible for soot formation, but all were limited to temporally uncorrelated single-shot measurements. Soot formation and oxidation in a turbulent flame is a transient phenomenon and one highly sensitive to residence time in the flamezone and local fluid dynamics. An effective way to separate chemical-kinetic (i.e. chemical reactions) and thermo-fluidic (e.g. particle condensation / agglomeration) effects would be to track fluid elements as they approach, pass through and convect downstream of the reaction zone of a flame and, in effect, perform the measurement in the local frame of reference of the soot particle itself. Although this is clearly impossible, a practical substitute is to acquire continuous, time-resolved planar measurements of the velocity field simultaneously with the LII soot measurement, and track elements as they pass through the field of view. With the development of high framerate CMOS cameras and high power diode-pumped solid state (DPSS) lasers, researchers have recently used simultaneous time-resolved LIF imaging of the hydroxyl $(\mathrm{OH})$ combustion radical and PIV to study transient combustion phenomena ranging from edge-flame propagation [17] to local flame extinction [18], flame hole re-ignition [19], engine misfire [20] and blow-out [21]. Development of a similar flow-tracking capability for LII measurements has been hindered however, by the relatively high peak laser fluence $\left(2 \mathrm{~mJ} / \mathrm{mm}^{2}\right.$ and above) required to accomplish 2D-LII and the difficulty of performing PIV in a densely sooting flame. 
The purpose of this paper is to describe a combined LII / PIV measurement system recently developed at the DLR Institute for Combustion Technology, with a $3 \mathrm{kHz}$ framerate and 0.67 second measurement duration, and to present initial results acquired with the system. The kHz-LII system is characterized and compared to conventional $10 \mathrm{~Hz}$ LII systems based on a non-linear LII response curve measured in a laminar propane diffusion flame. Critical limiting factors relating to the $\mathrm{kHz}$ LII technique are identified and discussed. The potential of this advanced combustion diagnostic is demonstrated by applying it to the study of a heavily sooting turbulent jet flame of ethylene. Sample mean and instantaneous data from this measurement series is presented and the results compared to data recently acquired [22] in the same test flame using conventional LII and PIV measurements. The results indicate the technique is both viable and yields interesting new insight into the turbulence-chemistry interactions associated with soot formation in turbulent flames. Surprisingly, initial results indicate that increasing the acquisition rate of the PIV measurements from $5 \mathrm{~Hz}$ to $3 \mathrm{kHz}$ also simplifies the sooting-flame experiment and improves measurement quality by significantly reducing the influence of background luminosity.

\section{Experimental setup}

\subsection{Laser-induced incandescence system}

The LII system consists of a frequency-doubled, Q-switched, diode-pumped solid state (DPSS) Nd:YAG laser (Edgewave IS-8IIE) and an intensified CMOS camera (LaVision, details below), as shown in Fig. 1. At $3 \mathrm{kHz}$, the laser delivered $5 \mathrm{~mJ} /$ pulse at $532 \mathrm{~nm}$, with an $8.5 \mathrm{~ns}$ pulse duration. The short pulse-duration is essential in order to reach sufficiently high fluence to excite LII using the relatively low energy pulses characteristic of kHz-rate DPSS lasers. A continuously variable beam attenuator consisting of a half wave plate and polarizing beamsplitter cube (for use in measuring the LII response curve) was mounted at the exit of the laser. The beam was formed into a thin sheet using a coated cylindrical lens $\left(f_{\text {LII, }}=1000 \mathrm{~mm}\right)$ and focused to a waist using a spherical lens $\left(f_{\text {LII,2 }}=1000 \mathrm{~mm}\right)$. A rectangular aperture was used to block the low fluence edges of the sheet, producing a sheet approximately $6 \mathrm{~mm}$ high. The LII laser sheet thickness was measured to be approximately $500 \mu \mathrm{m}$ at the probe volume using a burn-mark on photographic paper. The spatial profile of the beam was not measured as no beam profiling camera with sufficiently high framerate was available to image the pulses. Due to the associated uncertainties, we report laser pulse energies instead of fluence for the remainder of this paper. 
LII emission was detected perpendicular to the laser beam using a 10-bit, $1024 \times 1024$ pixel CMOS camera (LaVision HSS5) with an external two-stage, lens-coupled intensifier (LaVision HS-IRO). The camera was equipped with a $100 \mathrm{~mm}, \mathrm{f} / 2.8$ (Tokina) objective lens. Background flame luminosity was minimized using a $100 \mathrm{~ns}$ intensifier gate. Elastic scattering from soot and/or PIV particles at $532 \mathrm{~nm}$ was blocked using a bandpass filter (LOT 450 FS40-50) centred at $\lambda=455 \pm 15 \mathrm{~nm}$ (FWHM). The camera holds sufficient on-board memory (2.6 GB) for 2048 images (i.e., 0.68 seconds continuous imaging) at full resolution. It should be noted that LII signal exists only in the region illuminated by the LII excitation sheet (as defined by the response curve described later) and thus, the imaging array was not fully utilized in this experiment. Correction for camera and intensifier sensitivity was accomplished via normalization of the measured images with a 2048 frame ensemble average of a uniform white-field illumination lamp.

As current generation CMOS cameras (particularly those coupled with image intensifiers) are known to suffer from non-uniformity in pixel response and non-linearity in photon-to-signal conversion [23], the LII data presented below is qualitative and evaluation limited to phenomenological description. It should be noted however, that an extensive database of quantitative LII measurements acquired in the same flame using the conventional (low-framerate) LII technique [22] offers an excellent basis for comparison and recently developed pixel-by-pixel background characterization techniques [23] offer a viable path to more quantitative measurements in the foreseeable future.

\subsection{Particle image velocimetry system}

The PIV system consists of a Q-switched, dual-cavity DPSS laser (Edgewave, IS-6IIDE) and a high-speed CMOS camera (LaVision HSS5). The laser produces $2.6 \mathrm{~mJ}$ pulses at $532 \mathrm{~nm}$ with pulse durations of approximately $14 \mathrm{~ns}$ at repetition rates up to $10 \mathrm{kHz}$. In this study the system was operated at $3 \mathrm{kHz}$, synchronous with the LII measurement. The laser was formed into a thin, collimated sheet using three cylindrical lenses $\left(f_{\mathrm{PIV}, 1}=-38 \mathrm{~mm}, \mathrm{f}_{\mathrm{PIV}, 2}=250 \mathrm{~mm}\right.$, and $\left.\mathrm{f}_{\mathrm{PIV}, 3}=750 \mathrm{~mm}\right)$ and overlapped at a shallow angle $(<0.6$ degree) with the LII excitation sheet. This was accomplished using a mirror mounted sufficiently far $(1.9 \mathrm{~m})$ from the measurement volume. As this beam-combining technique inevitably results in non-parallel laser sheets, the intersection point of the two beams was set at the most probable flame location on the entry-side of the jet-flame (with respect to the laser sheets) and the PIV sheet was made sufficiently thick to ensure good overlap of the measurement volumes in the sooting 
region on that side of the flame. The resulting PIV laser fluence of $0.02 \mathrm{~J} / \mathrm{cm}^{2}$ or below is not relevant in LII categories and too small to cause particle evaporation.

Pulse separation for the PIV system was set to $20 \mu \mathrm{s}$. The LII excitation pulse was temporally interlaced between the first and second PIV pulse of each measurement cycle and timed to occur during the inter-frame readout period of the CMOS camera, rendering it invisible to the PIV system. The $10 \mu \mathrm{s}$ delay between the first PIV pulse and the LII measurement also eliminates the possibility any LII signal excited by the PIV laser being detected by the LII camera.

Mie scattering from titanium dioxide $\left(\mathrm{TiO}_{2}\right)$ particles (nominal diameter $0.5 \mu \mathrm{m}$ ) seeded into the flow was imaged onto a high speed CMOS camera (LaVision HSS5). The camera was mounted opposite to the LII camera and was equipped with a $100 \mathrm{~mm}, \mathrm{f} / 4$ (Tokina) objective lens. Flame luminosity, already minimal compared to conventional PIV cameras due to the short $\left(1 / 6000^{\text {th }}\right.$ second $)$ integration time of the CMOS sensor, was blocked with a $10 \mathrm{~nm}$ FWHM band-pass interference filter. The camera is equipped with sufficient on-board memory (2.6 GB) for 2097 image-pairs (i.e., 0.67 seconds imaging) at $768 \times 680$ pixel resolution. Spatial calibration of the particle images was accomplished using a dualplane, three dimensional imaging target (LaVision Type 7). Image mapping, calibration, and particle cross-correlations were completed using a commercial, multi-pass adaptive window offset crosscorrelation algorithm (LaVision DaVis 7.2). Final window size and overlap were $16 \times 16$ pixels and $50 \%$, corresponding to a vector resolution and spacing of $\approx 0.52 \mathrm{~mm}$ and $0.25 \mathrm{~mm}$, respectively. The particle images were processed using the extended dynamic range technique described in Boxx et al. [18], wherein vectors derived from the cross-correlation of image pairs in a given measurement cycle $(\Delta \mathrm{t}=20 \mu \mathrm{s})$ are filtered based on particle displacement and combined with vector fields produced from cross-correlation of particle images from the subsequent measurement cycle $(\Delta t=333 \mu \mathrm{s})$. Based on the \pm 0.1 pixel uncertainty of the cross-correlation peak-finding algorithm, the random uncertainty of the PIV measurements is estimated to be $\pm 0.16 \mathrm{~m} / \mathrm{s}$ for the inter-pulse separation and $\pm 0.0097 \mathrm{~m} / \mathrm{s}$ for the intercycle time separation.

\subsection{Flames Studied}

Two flames were used in this study: a laminar propane jet diffusion flame and a lifted turbulent jet flame of ethylene. The former was used to determine the response curve of the kHz-LII system, the latter to demonstrate its suitability as an applied combustion diagnostic. 
The laminar flame consisted of a circular ( $8 \mathrm{~mm}$ inner diameter) jet of propane ( $99.5 \%$ purity) issuing into a concentric, low-velocity co-flow of dry room-temperature air at atmospheric pressure. Propane was metered into the central tube at a rate of $17.3 \mathrm{~g} / \mathrm{min}$ via an electromechanical flow control unit (Brooks 5851S) and monitored throughout each experiment using a calibration standard Coriolis mass flow meter (Siemens Sitrans-FC Mass-Flo 2100, Model DI-3). The response curve of the LII system was derived based on measurements acquired $35 \mathrm{~mm}$ downstream of the burner exit, a position where soot concentration is almost constant with downstream distance and fluctuations in the radial position of the flame were minimal.

The lifted turbulent jet flame is based on the test case described recently in [22] and consists of a $2 \mathrm{~mm}$ diameter round jet of ethylene issuing into a concentric, low-velocity co-flow of dry, roomtemperature air. Ethylene ( $99.95 \%$ purity) was metered into the central tube at a rate of $10.4 \mathrm{~g} / \mathrm{min}$ via an electromechanical flow control unit (Bronkhorst F1C0-FAC-33-Z) and monitored throughout the experiment via a calibration-standard Coriolis mass flow meter (Siemens Sitrans-FC Mass-Flo 2100, Model DI-1.5). This corresponds to a bulk flow-velocity of $44 \mathrm{~m} / \mathrm{s}$ at the jet-exit, and jet-exit Reynolds number of 10000. The resulting flame is lifted and has a visible flame length of 400-500 mm. For the demonstration of the technique, two imaging regions were used: the first spanning $58-68 \mathrm{~mm}$ and the second $98-108 \mathrm{~mm}$ downstream of the jet-exit.

Extinction measurements by previous researchers [22] indicate the average maximum soot concentration in this flame is $0.54 \mathrm{ppm}$ and instantaneous soot concentrations can exceed $5 \mathrm{ppm}$.

\section{Results and Discussion}

\subsection{High-speed LII}

The correct interpretation of LII data depends on knowing the response characteristics of the measurement system to a given excitation laser fluence. This is typically determined by measuring a response curve of the system in a well-defined sooting flame. Conventional LII imaging systems are usually operated in the so-called 'plateau region' of the response curve [13,24]. In this region the integrated LII signal measured by the detector becomes almost independent of the fluence of the excitation laser.

Figure 2 shows the response curve for the LII system, measured in the laminar propane diffusion flame described above. It was measured by taking 1000-shot LII image sequences of the flame over excitation energies ranging from 0 to $5 \mathrm{~mJ} /$ pulse. The ensemble-average of LII signal, integrated over 
the sooting regions of the flame (shown by the boxes on the representative mean-image) is used as a marker for LII response. As the sheet profile was seen to be inhomogeneous in the vertical direction, it was impossible to define a single, global fluence for the LII system. Instead, three integration window sizes were used and the results compared for consistency. As beam-steering, laser attenuation and sheet divergence may affect the excitation laser as it propagates through the flame the response curve was measured on both the laser entrance and the laser exit side of the laminar flame. Finally, as LII response curves are known to be highly dependent on laser-sheet profile and collection optics configuration [25], the measurement was made with the optics, camera settings and intensifier gate identical to that used to image the sooting turbulent jet flame. As can be seen in Fig. 2, the results were uniformly consistent. All measured LII response curves increase in a quasi-linear fashion up to pulse-energy $1.7 \mathrm{~mJ}$, after which the integrated signal plateaus and subsequently only minor changes are observed with increasing excitation energy. Similar behaviour (not shown here) is found for very small evaluation rectangles $(3 \times 3$ pixels). Deterioration of the excitation beam profile quality is the most probable explanation for different signal levels in the response curves. For the turbulent flame characterized below, only the laser entrance of side of the soot distribution was overlapped with the PIV field of view.

Figure 3 shows a sequence of LII images acquired in the sooting turbulent jet flame at $3 \mathrm{kHz}$. To illustrate the signal-to-noise ratio and image quality achievable with the system, the images in Fig. 3 are not corrected for noise, camera sensitivity or laser sheet profile. Despite this, soot structures are clearly identifiable and well resolved across the width of the flame and can be easily tracked from one frame to the next. A comparison of the images in Fig. 3 with those acquired in the same flame and imaging location with a conventional LII system [22] shows soot structures of very similar size and shape, a qualitative indication of similar detection sensitivity, albeit over a smaller imaging region.

Figure 3 illustrates that individual soot structures can be identified and tracked from frame-to-frame. Remarkably, a significant influence of the laser radiation on the soot distribution or LII signal reduction is not observed. This gives rise to the question whether individual soot particles have been subject to multiple excitations and possibly a significant change in the soot characteristics. PIV measurements described below indicate that multiple excitations are likely. For example, at $\mathrm{h} \approx 100 \mathrm{~mm}$ and $\mathrm{r} \approx 10 \mathrm{~mm}$ where high soot concentrations are observed in Fig.3, the mean axial velocity is on the order of $2 \mathrm{~m} / \mathrm{s}$ (see Fig.5b). Thus, from shot to shot $(0.333 \mathrm{~ms})$ the fluid is convected on the average by about $0.7 \mathrm{~mm}$ in axial direction. At $\mathrm{r} \approx 8 \mathrm{~mm}$ it is about twice the distance. The instantaneous out-of-plane velocity (circumferential velocity component) was not determined in this study. However, it is expected to be 
significantly smaller than the axial velocity so that a fluid element probably stays within the laser sheet of $0.5 \mathrm{~mm}$ thickness for several shots. This estimation indicates that individual soot clouds are probably subject to several laser shot exposures. It is well established [26] that even at relatively low laser fluences (ca. $1.5 \mathrm{~mJ} / \mathrm{mm}^{2}$ ), LII excitation can have measurable effects on soot morphology. Recent work [27] has shown that these effects extend to the optical properties of the soot, indicating that multiple exposures of the same soot particle may result in a spurious measurement. This effect was not accounted for in the present measurements and is beyond the scope of this paper. We note, however, the peak laser fluence used for LII in this study is not far beyond that shown to induce initial changes in soot properties, and significant effects of multiple exposures were not observed in our image sequences.

A further point should be kept firmly in mind in studying image sequences of this sort; that soot is not a conserved scalar and it is impossible to determine with certainty the origin of soot appearing in a given region of an LII image, or where it goes when it disappears. It may form in-plane through chemical reaction or simply convect into the measurement plane through bulk fluid motion. Soot disappearing from the field of view may have been oxidized, de-agglomerated and dispersed by fluid-dynamic shear stress or have propagated out of the plane of laser excitation. Stereoscopic PIV provides a means to identify regions where through-plane convection is a possible explanation, but even then does not answer the question with certainty. Thus, special care must be taken in drawing global conclusions based on planar measurements such as these.

\subsection{Highspeed PIV}

Figure 4 shows two pairs of unprocessed (raw) particle images acquired in the sooting turbulent jet flame alongside a pair of images taken in the flame using a conventional $5 \mathrm{~Hz}$ system to illustrate a somewhat surprising practical advantage of the $\mathrm{kHz}$-PIV technique over its conventional low-framerate counterpart. Both image pairs show luminous soot structures as well as the Mie scattering from the seed particles. While the images recorded with the high-speed system exhibit similar signal quality, the second image obtained with the $5 \mathrm{~Hz}$ system is dominated by luminous soot or flame structures.

The overwhelmingly dominant imaging technology used in conventional PIV systems is the interlinetransfer CCD camera. These cameras capture two images in rapid succession by exposing a CCD imaging array, rapidly transferring the resulting charge into an array of on-sensor storage registers and immediately beginning the exposure of the second frame, thus allowing the sensor to capture a second frame before the first is completely read out. Although this allows two frames to be acquired in rapid 
succession it has a major drawback when used in highly luminous sooting flames, namely significant different exposure times for first and second image. Whereas the first frame may have a submicrosecond exposure time, the second frame may be exposed as long as 30 milliseconds or more, resulting in perhaps orders of magnitude greater soot luminosity being acquired in the second frame. As the PIV technique relies on the cross-correlation of two particle images, this makes it challenging to obtain reliable vector yields. CMOS cameras however, do not have this problem inasmuch as they run continuously at double the framerate of the pulsed laser source, capturing each laser pulse on separate, equally exposed frames. Although some soot luminosity is still captured during each exposure, the equal exposure time serves to minimize its effect on the PIV cross-correlation function. In addition, the absolute exposure time of the PIV image is one over twice the framerate, meaning the higher the framerate, the lower the exposure time and the less soot luminosity acquired in a given image. Although it is clearly possible to mitigate some of the problems associated with different exposure times characteristic of interline transfer CCD cameras, for example with narrower bandpass filters, smaller imaging apertures, larger PIV interrogation windows or more exotic shuttering techniques, each method degrades the overall system performance in its own way. The short, constant exposure periods characteristic of highspeed CMOS cameras eliminates the problem altogether, thus making them more suitable for PIV in highly luminous sooting flames.

Figure 5a shows the ensemble-averaged velocity field measurements for each of the two regions measured in the sooting turbulent jet flame with the highspeed LII/PIV system, together with the mean velocity field measured by Köhler et al. [22] using conventional 5 Hz PIV. Figure 5b shows horizontal profiles at 60 and $100 \mathrm{~mm}$ height above the burner exit for each of the datasets for comparison. We note an apparent misalignment of the $5 \mathrm{~Hz}$ data inasmuch as the peak velocity in that profile occurs slightly to the right of the centerline. If one corrects for this misalignment, the overlap in the profiles is even better at both locations showing a good agreement. The kHz-rate PIV measurements show smoother mean contours, indicative of more fully converged mean data. This results from our having used 2096 PIV measurements at $3 \mathrm{kHz}$ to compute the mean velocity field shown, compared to 200 PIV measurements at $5 \mathrm{~Hz}$ used by Köhler et al. [22]. Figure 5 also shows the significantly higher spatial resolution of the $\mathrm{kHz}-\mathrm{PIV}$ measurements compared to the $5 \mathrm{~Hz}$ measurements [22]. Although the choice of PIV resolution in the present work was driven by a desire to match the field of view of the LII system, it is clear from the sample LII/PIV sequence of Fig. 6, it resulted in an excellent match to the length scales of the temporally developing soot structures at the measurement location. 


\subsection{Simultaneous high-speed LII and PIV}

Figure 6 shows every second frame of a representative LII / PIV measurement sequence acquired with this system in the sooting turbulent jet flame. The PIV imaging region spans $98-108 \mathrm{~mm}$ downstream of the jet-exit. The mean velocity field at this location has been subtracted from the instantaneous vector plots to better isolate and identify fluid-dynamic effects in the frame of reference of the soot structures. Although a detailed analysis of the spatiotemporal interaction of soot structures and the local flowfield is clearly beyond the scope of this work, some interesting phenomena are observable in Fig. 6. In this sequence, we see a soot structure spanning approximately half the jet-width propagate through the field of view of the measurement system, deforming as it interacts with higher velocity fluid near the jetcenterline. In frame 1, the downstream edge of the structure is thin and resides in the periphery of the jet at a radial position of approximately $10 \mathrm{~mm}$. By frame 3, the downstream edge of the structure has moved beyond the field of view and the structure is seen to have widened considerably and now spans all the way from the centerline to the outer periphery of the jet. In frame 4 , as the trailing edge of the structure propagates up through the field of view we see it begin to deform, with the portion closer to the high-velocity centerline swept downstream faster than that laying in the periphery. By frame 5, only a small portion of the trailing edge of the structure remains visible in the image.

Despite the LII data in the present work being non-quantitative, comparison of the data in Fig. 6 with previous measurements in the same flame yield a logical explanation of what we see in this image sequence. Comparing the spatial location of the soot filament in frame 1 with the mean velocity fields shown in Fig. 5, it is clear the structure resides at the outer edge of the fuel jet. Comparison with previously published $\mathrm{OH}^{*}$ chemiluminescence data [22], one sees this soot structure also resides very close to the mean reaction zone location. Absent a direct measurement of the instantaneous reaction zone location (e.g. via LIF imaging of $\mathrm{CH}$ or $\mathrm{OH}$ ) it is impossible to say with certainty, but it is highly probably the soot structure in frame 1 is enveloped by a high velocity fuel flow on the left side and a reaction zone on the right. It is well established [28] that shear affects soot formation and agglomeration, and one would expect rapid oxidation and burnout of soot in the reaction zone, resulting in a thin, filament or sheet-like soot structure there. Comparing the LII images with the instantaneous flowfields in frames 2 and 3 , we observe that a.) the structures become significantly wider near the jet centerline and b.) the structures reside in a region of the flow that, in the local frame of reference resulting from having subtracted the mean velocity field, resembles the region immediately upstream of 
a stagnation-point. Thus, in the moving reference frame of the fluid element, the thickest part of the soot structure exists in a low-velocity region where residence times are longer and fluid-dynamic extensive strain is minimal. Finally, the thickest point of the soot structure also exists closer to the centerline, where one would expect to find little oxygen to burn out the soot. In frame 4, the soot structure is aligned with the local stagnation point flow and has begun to thin. By frame 5, the bulk of the structure is beyond the field of view. Taken together, a reasonable explanation of this sequence is that the soot formation here is being driven by a large-scale vortex structure propagating up through the jet, with the uppermost edge impinging upon the reaction zone and its wake inducing a region conducive to soot formation. Although this result is unsurprising, for it is known that regions of low strain, high fuel concentration and long residence time are conducive to soot formation, Fig. 6 is illustrative of the power of simultaneous highspeed LII and PIV imaging. With access to both the temporally developing soot and velocity field information, a greater fundamental understanding of the turbulence-chemistry interaction responsible for soot formation and reduction is possible.

\section{Conclusion}

Simultaneous planar laser induced incandescence (LII) and particle image velocity (PIV) measurements have been performed in a sooting turbulent jet diffusion flame at a sustained repetition rate of $3 \mathrm{kHz}$ employing diode pumped solid state lasers. Using a pulse energy of $5 \mathrm{~mJ}$ at $532 \mathrm{~nm}$ with a pulse duration of $8.5 \mathrm{~ns}$, high quality LII images were achieved in a sheet of $6 \mathrm{~mm}$ height. The soot structures can be tracked from frame-to-frame reflecting the temporal development of the soot distribution. The question whether distinct soot particles were subject to multiple LII laser light exposures can not be answered unambiguously, but simultaneous acquired velocimetry data indicates it is likely. Importantly, the LII images show no indication of changes of the size or morphology of soot particles as a result of this.

High-speed PIV measurements were performed using $\mathrm{TiO}_{2}$ seed particles of $0.5 \mu$ diameter. Compared to "classical" PIV measurements with interline transfer CCD cameras, the current setup with a high-speed CMOS camera resulted in a high signal-to-background ratio and thus better image quality for the second frame of a PIV image pair. The reason is a significantly reduced exposure time for the second frame by which the background from flame luminosity is strongly suppressed. In this way, high quality PIV measurements were performed despite the luminous soot radiation. The simultaneous application of LII and PIV at $3 \mathrm{kHz}$ enables a deeper insight into the interaction between the flow-field 
and the soot structures. In an example sequence it is demonstrated that high soot concentrations are correlated with low relative flow velocities (long residence time) and low extensive strain.

The results obtained in this sooting turbulent $\mathrm{C}_{2} \mathrm{H}_{4}$ jet flame show that a combined LII/PIV measuring system is able to generate high-quality results at repetition rates that enable the tracking of temporal development. It thus has the potential to significantly extend the understanding of soot formation and oxidation phenomena in combustion systems of fundamental and applied technical interest.

\section{Acknowledgements}

The authors wish to thank Brian Crosland for helpful discussions and Dr. Campbell Carter of the Air Force Research Laboratory for providing the co-flow burner used in this study. 


\section{References}

[1] A.C. Eckbreth, J. Appl. Phys. 48, 4473-4479 (1977)

[2] L.A. Melton, Appl. Opt. 23, 2201-2208 (1984)

[3] C.R. Shaddix, K. Smyth, Combust. Flame 107, 418-452 (1996)

[4] S. Will, S. Schraml, A. Leipertz, Proc. Combust. Inst. 26, 2277-2284 (1996)

[5] J.E. Dec, A.O. zur Loye, D.L. Siebers, SAE Technical paper 910224 (1991)

[6] B. Bougie, L.C. Ganippa, A.P. van Vliet, W.L. Meerts, N.J. Dam, J.J. ter Meulen, Combust. Flame 145, 635-637 (2006)

[7] B.F. Kock, B. Tribalet, C. Schulz, P. Roth, Combust. Flame 147, 79-92 (2006)

[8] M. Braun-Unkhoff, A. Chrysostomou, P. Frank, E. Gutheil, R. Lückerath, W. Stricker, Proc. Combust. Inst. 27, 1565-1572 (1998)

[9] M. Hofmann, W.G. Bessler, C. Schulz, H. Jander, Appl. Opt. 42, 2052-2062 (2003)

[10] O. Lammel, K.P. Geigle, R. Lückerath, W. Meier, M. Aigner, Proc. ASME Turbo Expo 2007, Power for Land, Sea and Air, 14.-17.05.2007, Montreal (Canada), Paper GT2007-27902

[11] R. Snelling, G. J. Smallwood, R. A. Sawchuk, W. S. Neill, D. Gareau, D. J. Clavel, W. L. Chippior, F. Liu, Ö. L. Gülder, SAE Tech. Paper 2000-01-1994 (Society of Automotive Engineers, Warrendale, Pa., 2000)

[12] J.D. Black, M.P. Johnson, Aerosp. Sci. Technol. 14, 329-337 (2010) 
[13] R.J. Santoro, C.R. Shaddix, "Laser-induced incandescence”. In Kohse-Höinghaus K., and Jeffries J. (Eds.) Applied Combustion Diagnostics, Taylor and Francis, London (2002)

[14] C. Schulz, B.F. Kock, M. Hofmann, H. Michelsen, S. Will, B. Bougie, R. Suntz, G. Smallwood, Appl. Phys. B, 83, 333-354 (2006)

[15] S.-Y. Lee, S.R. Turns, R.J. Santoro, Combust. Flame 156, 2264-2275 (2009)

[16] Q.N. Chan, P.R. Medwell, P.A.M. Kalt, Z.T. Alwahabi, B.B. Dally, G.J. Nathan, Proc. Combust. Inst. 33, 791-798 (2011)

[17] C. Heeger, B. Böhm, S.F. Ahmed, R. Gordon, I. Boxx, W. Meier, A. Dreizler, E. Mastorakos, Proc. Combust. Inst. 32, 2957-2964 (2009)

[18] I. Boxx, M. Stöhr, C. Carter, W. Meier, Appl. Phys. B 95, 23-29 (2009)

[19] A.M. Steinberg, I. Boxx, C. Arndt, J.H. Frank, W. Meier, Proc. Combust. Inst. 33, 1663-1672 (2011)

[20] C.M. Fajardo, V. Sick, SAE Paper 2009-01-0651 (2009)

[21] M. Stöhr, I. Boxx, C. Carter, W. Meier, Proc. Combust. Inst. 33, 2953-2960 (2011)

[22] M. Köhler, K.P. Geigle, W. Meier, B.M. Crosland, K.A. Thomson, G.J. Smallwood, Appl. Phys B, (2011), DOI: 10.1007/s00340-011-4373-y (2010)

[23] V. Weber, J. Brübach, R.L. Gordon, A. Dreizler, Appl. Phys. B Review (2010)

[24] P.O. Witze, S. Hochgreb, D. Kayes, H.A. Michelsen, C.R. Shaddix, Appl. Opt. 40, 2443-2452 (2001) 
[25] H. Bladh, P.E. Bengtsson, Appl. Phys. B 78, 241-248 (2004)

[26] R.L. Vander Wal, T.M. Ticich, A.B. Stephens, Appl. Phys. B 67, 115-123 (1998)

[27] K. Thomson, K.P. Geigle, M. Köhler, G.J. Smallwood, D.R. Snelling, Appl. Phys. B, (2011), DOI 10.1007/s00340-011-4449-8

[28] M. E. Decroix, W. L. Roberts, Combust. Sci. Technol. 160, 165-189 (2000) 


\section{List of Figures}

Figure 1: Setup for the combined LII/PIV experiment running at $3 \mathrm{kHz}$ on a lifted turbulent jet flame.

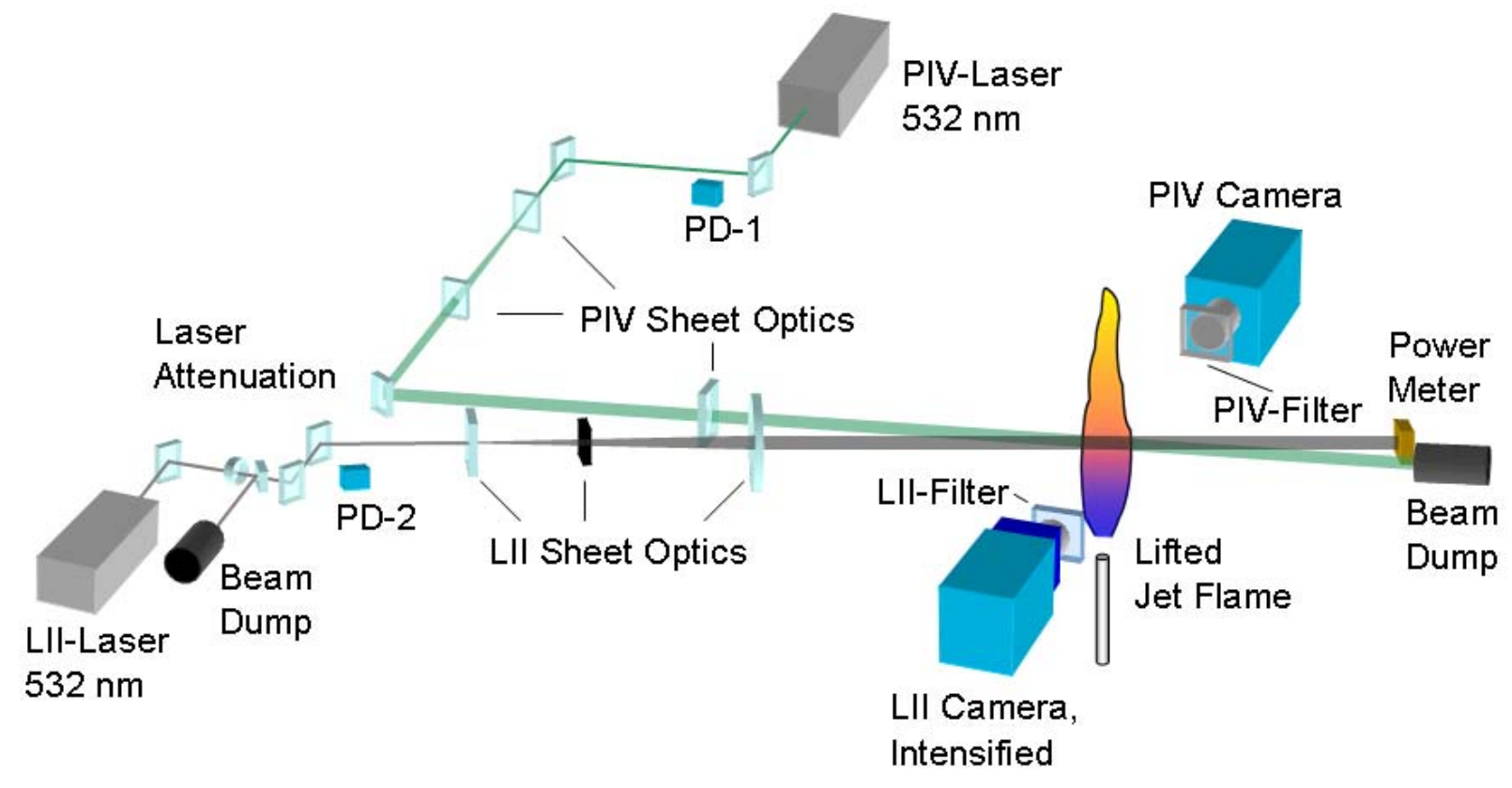


Figure 2: LII signal as a function of energy. The averaged intensity in three regions is used to observe inhomogeneities in the used laser sheet for the laser entrance side or laser exit side. The image indicating the analysed rectangles is an average of 1000 single shots excited at $4.7 \mathrm{~mJ}$.

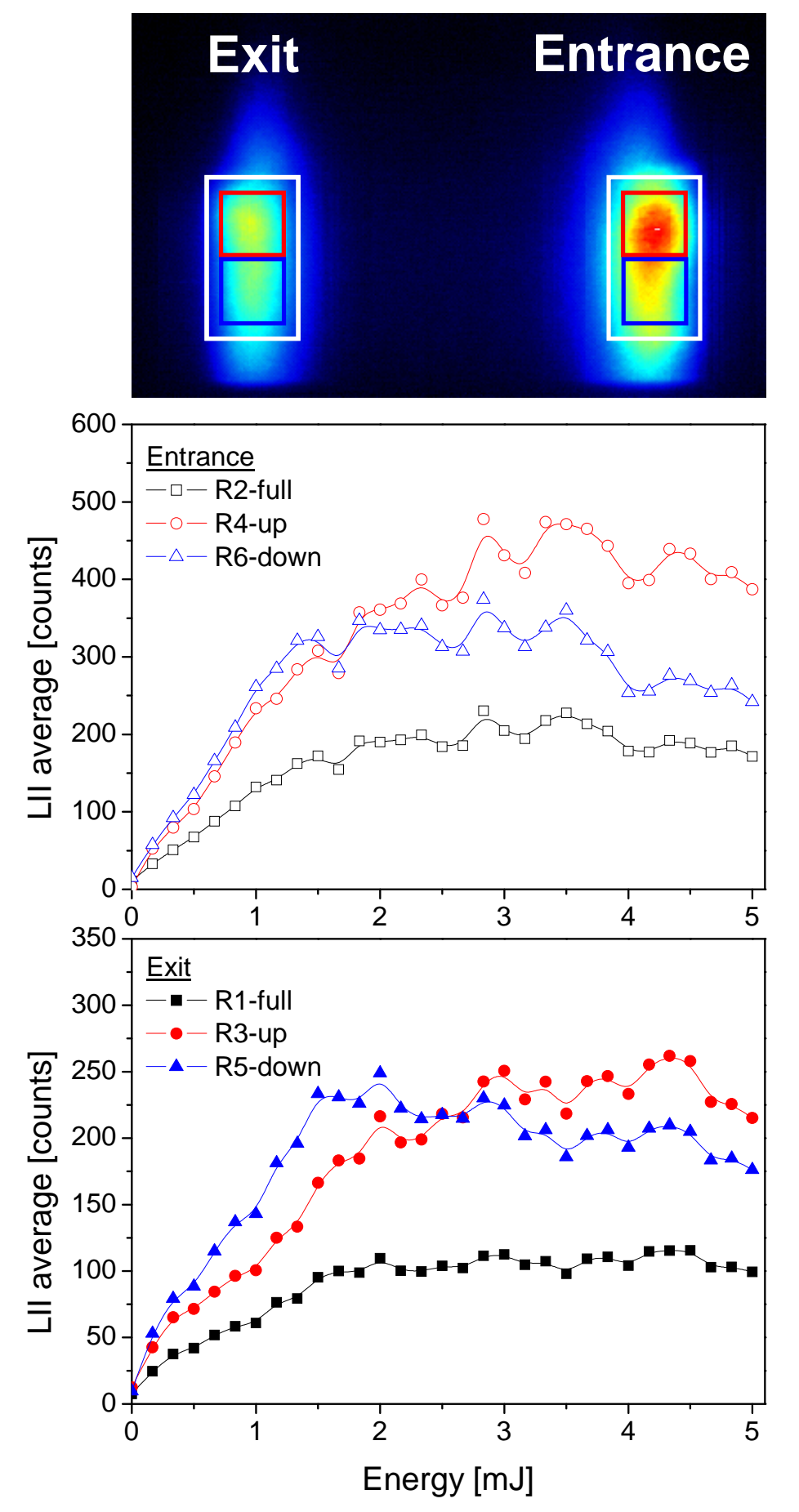


Figure 3: Sequence of instantaneous soot structures from the lifted ethelyne/air jet flame running at $3 \mathrm{kHz}$. An excitation pulse energy of $4.7 \mathrm{~mJ}$ is chosen for all soot concentration imaging measurements.

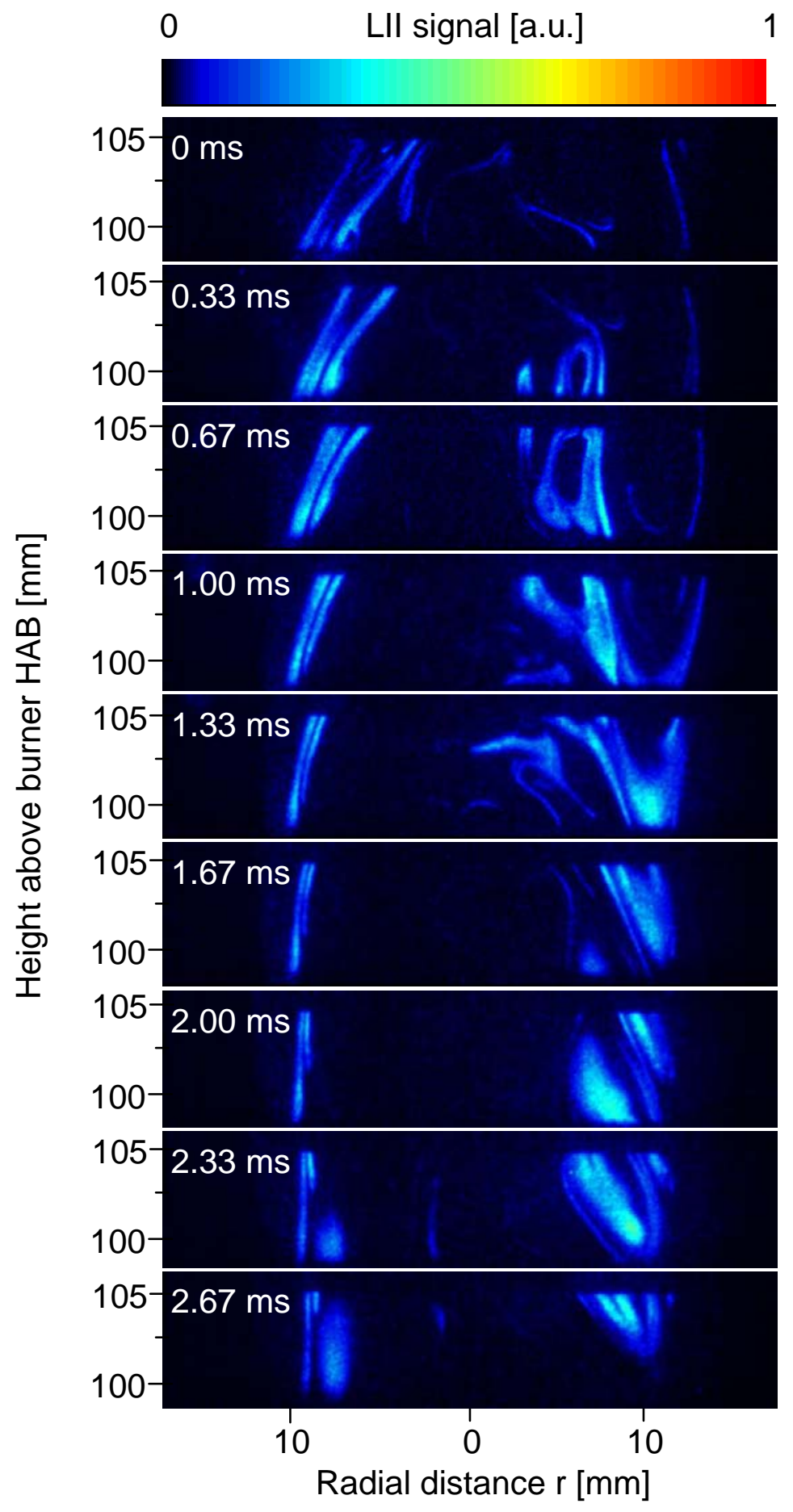


Figure 4: Comparison of raw particle images in the sooting turbulent jet flame; a,b) image pair for 3 $\mathrm{kHz}$ PIV and c,d) image pair for conventional $5 \mathrm{~Hz}$ system.
a) $3 \mathrm{kHz}$ - Frame 1
b) $3 \mathrm{kHz}$ - Frame 2
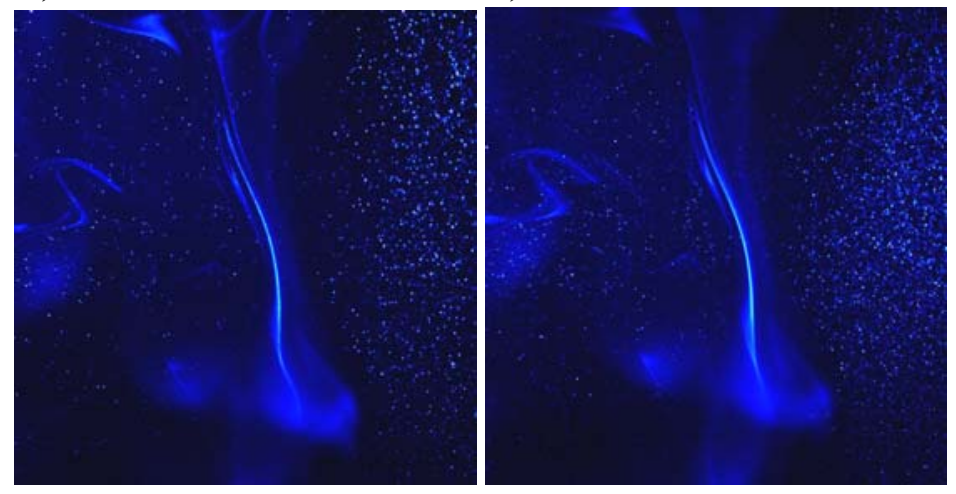

c) $5 \mathrm{~Hz}-$ Frame 1

d) $5 \mathrm{~Hz}$ - Frame 2
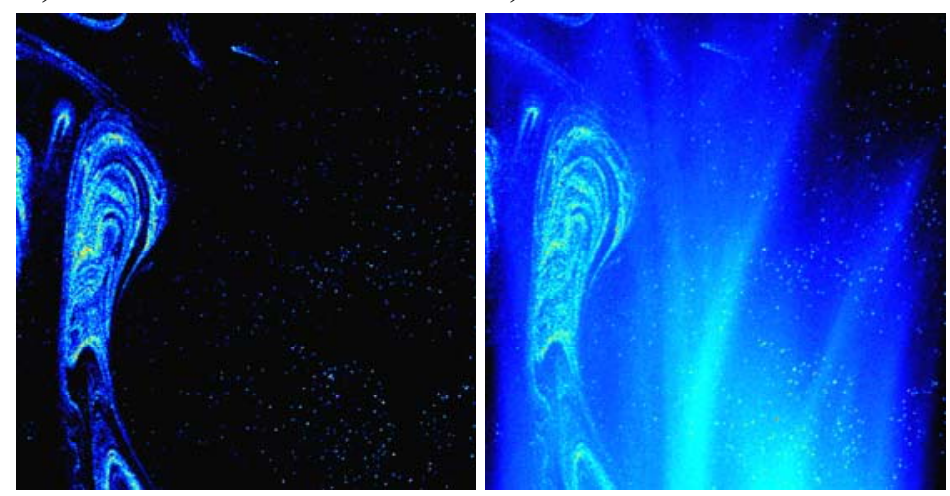
Figure 5: Comparison of high-speed (3 kHz) and conventional (5 Hz, [22]) PIV measurements in the sooting ethylene/air jet flame. a) Comparison of velocity contour plot from $5 \mathrm{~Hz}$ measurement (left) and $3 \mathrm{kHz}$ measurement (right). b) Horizontal velocity profiles for selected heights at $\mathrm{HAB}=60 \mathrm{~mm}$ and $100 \mathrm{~mm}$.

a)

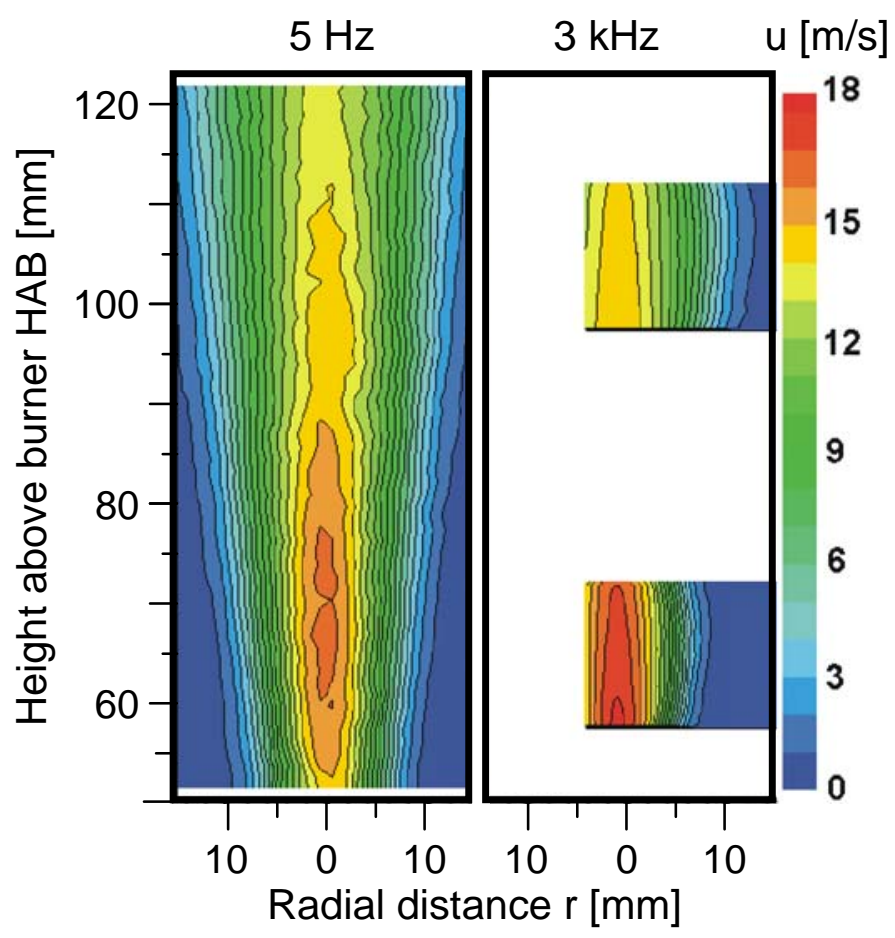

b)

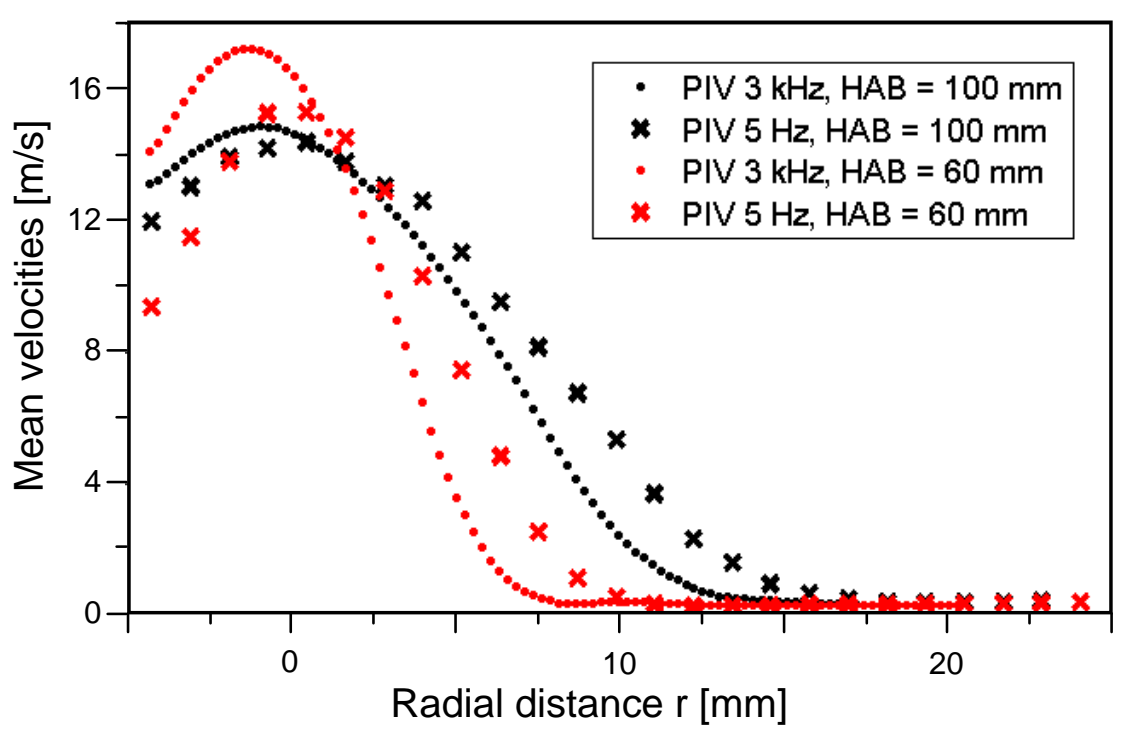


Figure 6: Sample measurement sequence of simultaneous $3 \mathrm{kHz}$ PIV/LII for the sooting ethylene/air jet flame.

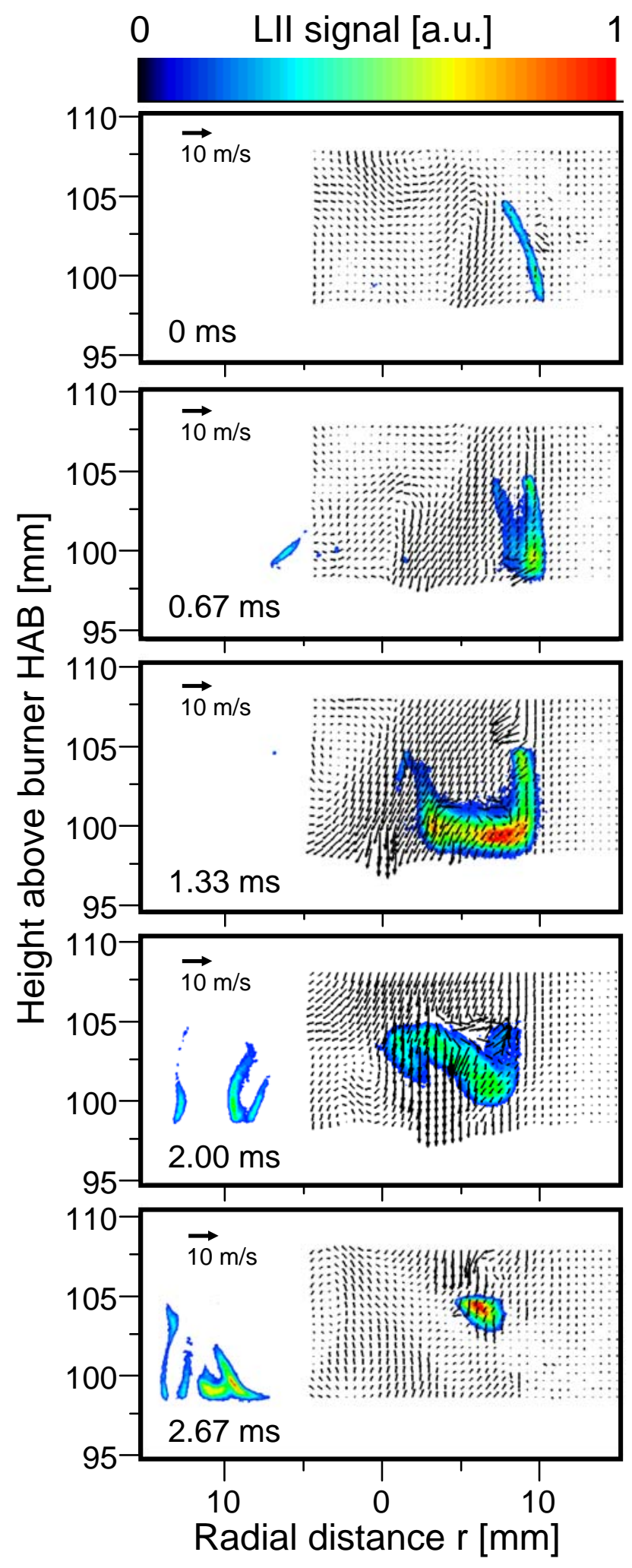

